\title{
Ultra-acute increase in blood glucose during prehospital phase is associated with worse short-term and long-term survival in ST-elevation myocardial infarction
}

\author{
Hanna Vihonen ${ }^{1 *}$, Ilkka Tierala ${ }^{2}$, Markku Kuisma ${ }^{3}$, Jyrki Puolakka ${ }^{3}$, Jukka Westerbacka ${ }^{4}$ and Jouni Nurmi ${ }^{1}$
}

\begin{abstract}
Background: The current study was to investigate the blood glucose changes in ultra-acute phase in patients with ST-elevation myocardial infarction (STEMI) and its associations with patient outcome.

Methods: This study was a retrospective population-based observational study utilizing prospectively collected registry data complemented with laboratory data. All adult patients with STEMI treated by emergency medical services (EMS) in the city of Helsinki from January 2006 to December 2010 were included in the study. Both prehospital and hospital admission glucose values were available from $152(32 \%)$ of all STEMI patients $(n=469)$.

Results: Change in blood glucose from prehospital phase to emergency department admission was significantly higher in non-survivors within 30 days compared to survivors (+1.2 \pm 5.1 vs. $-0.3 \pm 2.4$ mmol/I [mean $\pm \mathrm{SD}$ ], $\mathrm{P}=0.03$ ). Furthermore, the 3-year survival rate was significantly lower in patients with an evident $(\geq 2 \mathrm{mmo} / \mathrm{l})$ rise in blood glucose $(P=0.02)$. In patients with impaired left ventricle function (best ejection fraction $<40 \%$ ), blood glucose increased more compared to patients without it $(1.2 \pm 2.9 \mathrm{vs} .0 .4 \pm 2.7 \mathrm{mmol} / \mathrm{l}, \mathrm{P}=0.01)$. Increase in glucose was correlated with peak myocardial creatinine kinase $(r=0.17, P=0.04)$ as a marker of increased size of infarct, but not with glycosylated haemoglobin A1C as a marker of chronic hyperglycaemia $(r=-0.12, P=0.27)$.

Conclusions: In patients with STEMI, ultra-acute hyperglycaemia during prehospital phase is associated with increased mortality, impaired cardiac function and increased size of infarct.
\end{abstract}

Keywords: Glucose, Myocardial infarction, Prehospital

\section{Background}

Hyperglycaemia characterizes up to $50 \%$ of patients admitted with ST-elevation myocardial infarct (STEMI). Of those, 20-25\% have previously diagnosed diabetes [1]. The non-diabetic patients may have stress-induced hyperglycaemia due to increased levels of insulin counterregulating mediators such as proinflammatory cytokines, epinephrine, cortisol and tumour necrosis factor -alpha [2]. On the other hand of hyperglycaemic patients without previous diabetes at the time of STEMI, up to $40 \%$ actually were found having impaired glucose intolerance and

\footnotetext{
* Correspondence: hanna.vihonen@hus.fi

'Department of Anaesthesia and Intensive Care, Helsinki University Central Hospital, P.O. Box 340, 00029, HUS, Helsinki, Finland

Full list of author information is available at the end of the article
}

25\% having diabetes three months after discharge [3]. Hyperglycaemia at admission in STEMI patients, regardless of having diabetes or not, is an independent predictor of in-hospital and long-term adverse outcomes like heart failure, cardiogenic shock and death [4-6]. For every $1 \mathrm{mmol} / \mathrm{l}$ increase in blood glucose level, there is a $4 \%$ increase in mortality in non-diabetic subjects and 5\% increase in diabetic subjects [2]. Glucose levels of STEMI patients before arriving to hospital have not been described.

Whether treatment of hyperglycaemia improves outcome has not yet been definitely proved. The interventions to modify glucose metabolism have been initiated in most studies relatively late. For example, in the DIGAMI-II treatment was started 13 hours after first symptoms of 
acute myocardial infarction (AMI) and normoglycaemia was not achieved [7]. Recently, early management of dysglycaemia in acute myocardial ischemia has been studied. Selker et al. have shown prehospital glucoseinsulin-potassium to decrease hospital mortality and cardiac arrest incidence of patients with acute coronary syndrome [8]. We have previously demonstrated that hyperglycaemia of stroke patients can be effectively treated in the prehospital phase by paramedics [9]. We also have demonstrated in patients resuscitated from out-of-hospital ventricular fibrillation that early hyperglycaemic response develops during prehospital phase to patients with poor prognosis [10].

As ultra-acute hyperglycaemia is associated with poor prognosis in other conditions involving pathophysiology of ischemia and reperfusion and as being a relatively easily modifiable factor, we aimed to describe the blood glucose changes in prehospital phase in patients with STEMI and association of these glucose changes with outcome of these patients.

\section{Methods}

\section{Study design}

This study was a retrospective population-based observational study utilizing prospectively collected registry data complemented with laboratory data. The study protocol was approved by Helsinki University Hospital institutional review board. According to local legislation, patient consent was not required as only patient records and registry data were used.

\section{Patients}

We included all adult (over 18 years) patients with STEMI treated by emergency medical services (EMS) in the city of Helsinki (population of approximately 568 000) from January $1^{\text {st }} 2006$ to December $31^{\text {st }} 2010$. Only patients who were confirmed to have STEMI in the hospital were included. We excluded patients with missing prehospital and/or hospital admission glucose values.

\section{Treatment}

In the city of Helsinki, EMS transports all the STEMI patients to the single university teaching hospital. Early presenters ( $<3 \mathrm{~h}$ from pain-onset) without cardiogenic shock or significant heart failure are primarily treated with prehospital fibrinolysis (tenecteplase) and all others with primary-PCI. All patients were vigorously evaluated for fibrinolysis-failure and early angiography is actively performed. Criteria for successful fibrinolysis are 50\% resolution of ST-elevation and patient being painless and stabile in a time interval of 60-90 minutes. Rescue-PCI rate is $40 \%$. Patients with successful fibrinolysis undergo angiography within 24 hours.

\section{Setting and data sources}

The Helsinki EMS STEMI registry is a prospectively collected and includes all patients treated by EMS for STEMI. Emergency physician or medical supervisor is responsible of fulfilling the data into a structured data collection form after each case. Designated emergency physician verifies data based on EMS patient reports and hospital patient records.

Blood glucose was measured by EMS providers using the Optimum Xceed glucometer and MediSense Optimum electrodes (Abbott Laboratories, Alameda, CA). In these electrodes, the measurement is based on glucose dehydrogenase reaction and the glucometer is plasma calibrated. Prehospital blood glucose values were measured by ambulance personnel before arrival to hospital. Blood glucose measurement in the patients with chest pain is not mandatory in the standard operating procedure and thus depends on the consideration by the provider. Admission glucose values were included if taken within 24 hours of admission to hospital. Admission glucose was measured in central laboratory using hexokinase method in autoanalyser (Roche Diagnostics Hitachi 917, Hitachi Ltd., Tokyo, Japan). Prehospital glucose values were collected from the EMS patient reports. Admission glucose values and glycosylated haemoglobin $\mathrm{A} 1 \mathrm{c}\left(\mathrm{HbA}_{1 \mathrm{c}}\right.$, closest value measured within one year of STEMI) values were obtained from electronic laboratory database. Cardiac infarct marker myocardial creatininekinase (CK-MBm) was obtained from electronic laboratory database. The left ventricle ejection fraction was measured by a cardiologist using an echocardiography and four-chamber planimetry. Data of co-morbidities of patients (coronary syndrome, hypertension, diabetes) were obtained from STEMI registry. All other data were collected from hospital electronic patient records. Patients were followed up to three years to assess mortality using national population register data.

\section{Analysis}

The main outcome was 30-day survival and secondary outcomes impaired function (left ventricle ejection fraction <40\%), ST-resolution, major bleeding and heart failure. Change in blood glucose during prehospital phase to hospital admission was compared between outcome groups. Correlations of change in glucose with $\mathrm{HbA}_{1 \mathrm{c}}$ and $\mathrm{CK}-\mathrm{MBm}$ were calculated. Long-term survival up to three years was compared with subgroup with evident, over $2 \mathrm{mmol} / \mathrm{l}$, ultra-acute rise in blood glucose. This cut-off value was chosen because of inaccuracy of glucometers might cause erroneously smaller rise in glucose comparisons. Additionally, we have previously shown it is possible to modify blood glucose level equivalently during prehospital phase [9].

Categorical data was analysed using either Fisher's exact (two groups) test or chi-square test (more than 
Table 1 Available blood glucose values in prehospital and admission phase of all STEMI patients treated during the study period $(n=469)$

\begin{tabular}{llll}
\hline & & \multicolumn{2}{l}{$\begin{array}{l}\text { Admission glucose } \\
\text { measurement available }\end{array}$} \\
\hline $\begin{array}{l}\text { Prehospital glucose } \\
\text { measurement available }\end{array}$ & Yes & No \\
& Yes & $152(32 \%)$ & $6(1 \%)$ \\
& No & $287(62 \%)$ & $24(5 \%)$ \\
\hline
\end{tabular}

Patients with both prehospital and admission values available were included in the study.

two groups). Normally distributed data are reported as mean \pm standard deviation (SD) and skewed variables as median and inter-quartile range (IQR). Spearman's correlation was calculated for change in blood glucose and other continuing variables. Long-term survival was analysed using Log-rank (Mantel-Cox) test. All statistical analyses were carried out using GraphPad Prism 5.0 for Mac OS X (GraphPad Software, San Diego, CA).

\section{Results}

During the study period, the Helsinki EMS treated total of 469 patients with STEMI. Both prehospital and admission glucose values were available on one third of patients who were consequently included in the study (Table 1 ). Comparison of included and excluded patients is presented in Table 2, showing higher prevalence of diabetes and anterior STEMI within included patients. There was no difference in hemodynamic values between included and excluded patient groups. Median interval from onset of symptom to measurement of prehospital blood glucose was 65 (IQR 41 to 130) minutes, and to measurement of blood glucose after admission 170 (IQR 125 to 270) minutes.

Overall, no significant difference was observed between prehospital and admission glucose values $(8.8 \pm 3.3 \mathrm{mmol} / \mathrm{l}$ and $8.7 \pm 3.4 \mathrm{mmol} / \mathrm{l}$, respectively, $\mathrm{P}=0.50$ ). Change in glucose during prehospital phase in all patients was $-0.3 \pm$ $2.4 \mathrm{mmol} / \mathrm{l}$. This change did not differ between 38 diabetic patients and 114 non-diabetic patients $(0.2 \pm 3.2 \mathrm{mmol} / \mathrm{l}$ and $-0.3 \pm 2.7 \mathrm{mmol} / \mathrm{l}$, respectively, $\mathrm{P}=0.37$ ). Change during prehospital phase was not correlated with $\mathrm{HbA}_{1 \mathrm{C}}$ $(\mathrm{r}=-0.12, \mathrm{P}=0.27)$ or dose of intravenous metoprolol $(r=0.12, P=0.14)$. Distributions of prehospital and admission glucose values, as well as change of blood glucose, are shown in Figure 1.

Seventeen patients died within 30 days after admission. Increasing ultra-acute change during prehospital phase was significantly associated with 30-day mortality and impaired left ventricle ejection fraction (Table 3). Furthermore, change in glucose from prehospital to admission values was correlated with peak CK-MBm $(r=0.17$, $\mathrm{P}=0.04$ ).

Three-year survival was significantly lower in patients with evident, over $2 \mathrm{mmol} / \mathrm{l}$, increase in blood glucose from prehospital phase to admission with a hazard ratio of 3.78 (95\% CI 1.30 to $11.7, \mathrm{P}=0.02$ ). The survival curves of these groups are presented in Figure 2.

Table 2 Characteristics of patients with both prehospital and hospital admission glucose values available (included patients) and patients with missing glucose values (excluded patients)

\begin{tabular}{|c|c|c|c|c|}
\hline & All $N=469$ & $\begin{array}{l}\text { Included patients } \\
\qquad N=152\end{array}$ & $\begin{array}{l}\text { Excluded patients } \\
\qquad \mathrm{N}=317\end{array}$ & $P$ value \\
\hline Age (years), median, IQR & $62,55-72$ & $63,54-73$ & $61,55-72$ & 0.41 \\
\hline Sex, male (\%) & $336(72)$ & $106(70)$ & $230(73)$ & 0.58 \\
\hline Hypertension, \% & $182(39)$ & $66(43)$ & $116(37)$ & 0.16 \\
\hline Coronary artery disease, \% & $101(22)$ & $37(24)$ & $64(20)$ & 0.15 \\
\hline Diabetes, \% & $63(13)$ & $38(25)$ & $25(7.9)$ & $<0.0001$ \\
\hline Weight (kg), median, IQR & $75,60-86$ & $80,70-90$ & $80,70-90$ & 0.75 \\
\hline Admission glucose $(\mathrm{mmol} / \mathrm{l})$, median, IQR & $7.8,6.6-9.2$ & $7.8,6.4-9.8$ & $7.7,6.7-9.1$ & 0.79 \\
\hline Localization of infarct, anterior (\%) & $235(50)$ & $71(47)$ & $164(52)$ & 0.03 \\
\hline $\begin{array}{l}\text { Glycosylated haemoglobin } \mathrm{A} 1_{C}(\%)^{*} \text {, median, IQR/Glycosylated } \\
\text { haemoglobin } \mathrm{A} 1 \mathrm{C}(\mathrm{mmol} / \mathrm{l}) \text {, median IQR }\end{array}$ & $5.9,5.6-6.4 / 41,38-46$ & $6.0,5.7-6.6 / 42,39-49$ & $5.8,5.5-6.3 / 40,37-45$ & $0.02 / 0.02$ \\
\hline Systolic blood pressure $(\mathrm{mmHg})$, mean \pm SD & $142 \pm 34$ & $141 \pm 33$ & $143 \pm 34$ & 0.72 \\
\hline Pulse rate (beats per minute), mean \pm SD & $76 \pm 22$ & $75 \pm 20$ & $77 \pm 22$ & 0.34 \\
\hline \multicolumn{5}{|l|}{ Reperfusion strategy } \\
\hline Thrombolysis & 307 (65) & $110(72)$ & 197 (62) & 0.08 \\
\hline Primary $\mathrm{PCl}$ & $124(26)$ & $31(20)$ & $93(29)$ & \\
\hline No reperfusion therapy & $38(8.1)$ & $11(7.2)$ & $27(8.5)$ & \\
\hline
\end{tabular}

$\mathrm{IQR}$, interquartile range; $\mathrm{SD}$, standard deviation; $\mathrm{PCl}$, percutaneous coronary intervention.

*Available in 89 and 144 cases of included and excluded patients, respectively. 

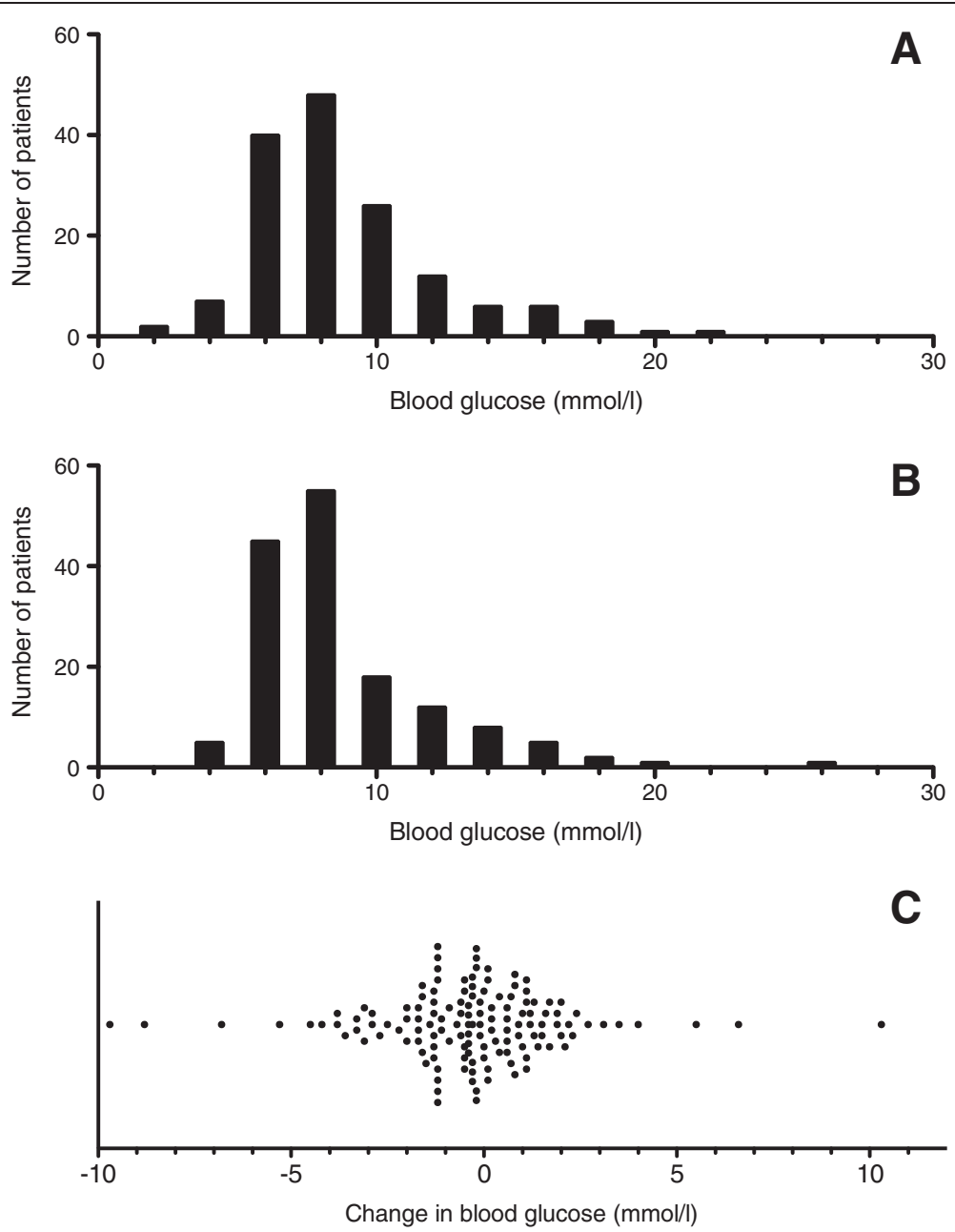

Figure 1 Distribution of blood glucose values in prehospital (panel A), admission (panel B) and ultra-acute change of prehospital and admission (panel C). Every dot represents a single patient.

\section{Discussion}

This is the first study to demonstrate an association between ultra-acute increase of blood glucose during prehospital phase and mortality in STEMI patients. Patients with increasing blood glucose had higher shortterm mortality. Interestingly, this outcome difference was remained in three-year long-term survival analysis. Early hyperglycaemic response seems to develop during prehospital phase and is more pronounced in patients with poor outcome. An ultra-acute increase in blood glucose was associated with decreased cardiac function and increase in marker of myocardial ischemia.

Previously it has been shown that hyperglycaemia at admission is associated with poor short-term outcome whereas chronic hyperglycaemia predicts long-term outcome in the patients with AMI [11]. Diabetes is wellknown risk factor for cardiovascular events. Acute hyperglycaemia may be an independent factor that potentially reflects more severe condition of the patient or alternatively has harmful effect per se, and thus is associated with higher mortality to AMI. In the current study, ultra-acute blood glucose change during prehospital phase was not associated with diabetes or level of $\mathrm{HbA}_{1 \mathrm{C}}$, as an indicator of chronic hyperglycaemia. This implies that these are two distinct phenomena. Earlier studies on acute hyperglycaemia have focused to single blood glucose at admission. The current study implies that ultra-acute change may have a significant role as well, even to long-term survival.

There are many potential mechanisms linking ultraacute hyperglycaemia to higher mortality and morbidity in acute STEMI. Stress-induced acute hyperglycaemia is caused by catecholamines, growth hormone, cortisol and cytokines. Acute increase in those counter regulatory hormones lead to excessive increase in hepatic glucose production and insulin resistance resulting in hyperglycaemia. Insulin resistance causes excessive free fatty acid production, which aggravates inflammation and hence worsens endothelial dysfunction together with 
Table 3 Association of outcome and blood glucose trend from prehospital phase to hospital admission

\begin{tabular}{|c|c|c|c|}
\hline & $\begin{array}{l}\text { Number } \\
\text { of patients }\end{array}$ & $\begin{array}{l}\text { Change in glucose } \\
\text { from prehospital to } \\
\text { admission (mmol/l) }\end{array}$ & $P$ value \\
\hline 30 days survival & & & 0.03 \\
\hline Yes & 135 & $-0.3 \pm 2.4$ & \\
\hline No & 17 & $1.2 \pm 5.1$ & \\
\hline Ejection fraction & & & 0.01 \\
\hline$\geq 40 \%$ & 126 & $0.4 \pm 2.7$ & \\
\hline$<40 \%$ & 26 & $1.2 \pm 2.9$ & \\
\hline Resolution of ST elevation & & & 0.92 \\
\hline Yes & 104 & $-0.2 \pm 2.5$ & \\
\hline No & 48 & $-0.1 \pm 3.5$ & \\
\hline Major bleeding & & & 0.07 \\
\hline No & 147 & $-0.2 \pm 2.8$ & \\
\hline Yes & 5 & $2.1 \pm 2.7$ & \\
\hline $\begin{array}{l}\text { Acute heart failure or } \\
\text { cardiogenic shock }\end{array}$ & & & 0.54 \\
\hline No & 120 & $-0.2 \pm 2.6$ & \\
\hline Yes & 32 & $0.1 \pm 3.5$ & \\
\hline
\end{tabular}

hyperglycaemia [12]. Endothelial dysfunction caused by hyperglycaemia is characterized by suppression of flowmediated vasodilatation. This is manifested as impaired microcirculation despite successful reperfusion [13]. Hyperglycaemia is associated with adverse effects on platelet function, fibrinolysis, coagulation and ischemic preconditioning of the heart. These directly damage the myocardium $[14,15]$. In the current observational study, hyperglycaemic response was associated with impaired myocardial function and greater infarct size although the definite mechanisms cannot be determined.

Whether glucose control using insulin is beneficial in STEMI is so far controversial. Major studies have found no outcome benefit of GIK infusion after STEMI $[7,16]$. However, GIK infusion does not lead rapid control of hyperglycaemia which has not been well studied yet. GIK has been preferred as insulin per se might have some beneficial effects in STEMI despite of glucose levels [17].

The main limitation of this study is that only one third of STEMI patients treated during the study period had sufficient data for analysis. This may result in a selection bias. In the study population diabetics and patients with anterior STEMI were overly presented. Data of potential previous heart failure was also absent. A retrospective design of the study limited also the study, although data collection was mainly based on prospectively collected registry data. The blood glucose values in the two time points were measured using different methods, which may have some effect on the results.

\section{Conclusions}

This study demonstrated that in patients with STEMI, ultra-acute hyperglycaemic response developing during prehospital phase is associated with decreased cardiac function, increased size of infarct and increased 30-day mortality. Furthermore, also long-term survival is lower

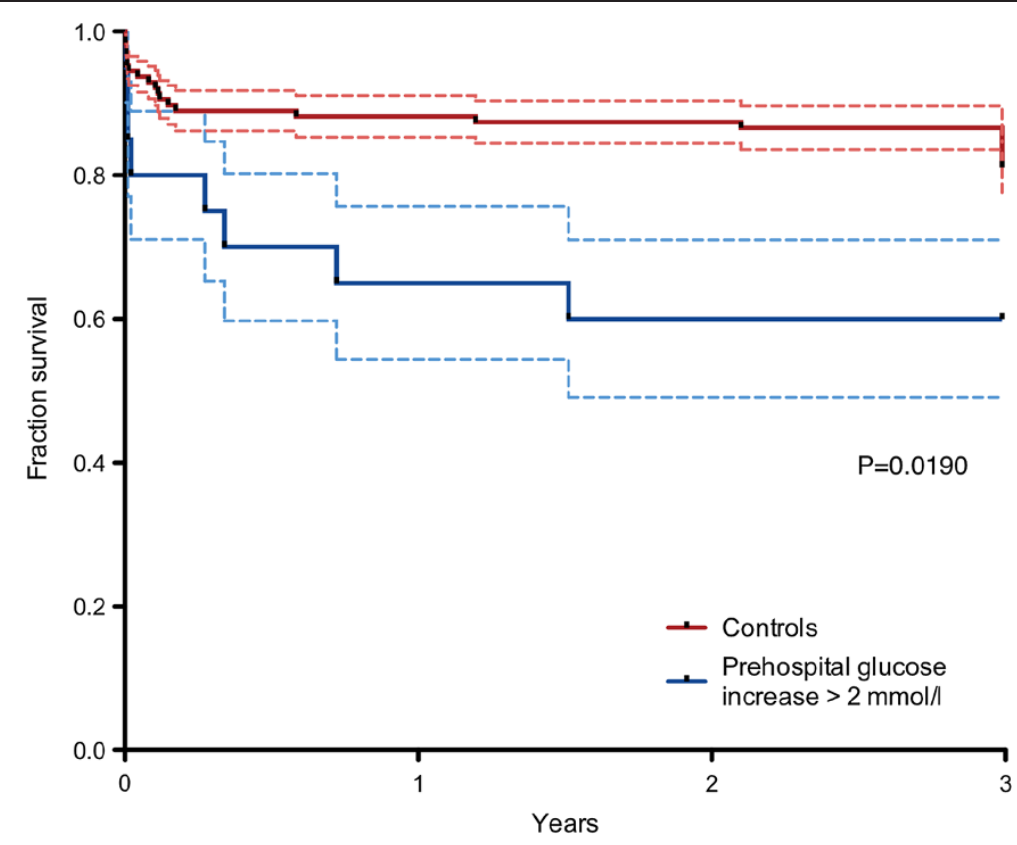

Figure 2 Survival curves of patients with and without ultra-acute over $2 \mathrm{mmol} / \mathrm{l}$ increase in blood glucose during pre-hospital phase. 
in patients with marked ultra-acute increase in blood glucose. These findings implicate need of further studies to evaluate results of modulation of this ultra-acute hyperglycaemia.

\section{Competing interests}

The authors declare that they have no competing interests.

\section{Authors' contributions}

HV and JP obtained the data. HV and JN researched data. HV, JN and IT wrote the manuscript. JP, JW and MK reviewed and edited the manuscript. All authors read and approved the final manuscript.

\section{Acknowledgments}

$\mathrm{HV}$ with $\mathrm{JN}$ takes responsibility for integrity of the data and the accuracy of the data analysis.

\section{Author details}

'Department of Anaesthesia and Intensive Care, Helsinki University Central Hospital, P.O. Box 340, 00029, HUS, Helsinki, Finland. ${ }^{2}$ Heart and Lung Centre, Helsinki University Central Hospital, Helsinki, Finland. ${ }^{3}$ Helsinki EMS, Department of Anaesthesia and Intensive Care, Helsinki University Central Hospital, Helsinki, Finland. ${ }^{4}$ Department of Medicine, Helsinki University Central Hospital, Helsinki, Finland.

Received: 17 June 2013 Accepted: 23 April 2014

Published: 1 May 2014

\section{References}

1. Zarich SW, Nesto RW: Implications and treatment of acute hyperglycemia in the setting of Acute Myocardial Infarction. Circulation 2007, 115:e436-e439.

2. Stranders I, Diamant M, van Gelder RE, Sprujit HJ, Twisk JWR, Heine RJ, Visser FC: Admission blood glucose level as risk indicator of death after myocardial infarction in patients with and without Diabetes Mellitus. Arch Intern Med 2004, 164:982-988.

3. Norhammar A, Tenerz A, Nilsson G, Hamsten A, Efendic S, Rydén L, Malmberg K: Glucose metabolism in patients with acute myocardial infarction and no previous diagnosis of diabetes mellitus: a prospective study. Lancet 2002, 359:2140-2144.

4. Wahab NN, Cowden EA, Pearce NJ, Gardner MJ, Merry H, Cox JL: Is blood glucose an independent predictor of mortality in acute myocardial infarction in the trombolytic era? J Am Coll Cardiol 2002, 40:1748-1754.

5. Nesto RW, Lago RM: Glucose a biomarker in acute myocardial infarction ready for prime time? Circulation 2008, 117:990-992.

6. Cooper J, Foo K, Deaner A, Knight C, Suliman A, Ranjadayalan K, Timmis AD: A single serum glucose measurement predicts adverse outcome across the whole range of acute coronary syndromes. Heart 2003, 89:512-516.

7. Malmberg K, Rydén L, Wedel H, Birkeland K, Bootsma A, Dickstein K, Efendic S, Fischer M, Hamsten A, Herlitz J, Hildebrandt P, MacLeod K, Laakso M, Torp-Pedersen C, Waldenström A: FASTTRACK Intense metabolic control by means of insulin in patients with diabetes mellitus and acute myocardial infarction (DIGAMI 2): effects on mortality and morbidity. Eur Heart J 2005, 26:650-661.

8. Selker HP, Beshansky JR, Sheehan PR, Massaro JM, Griffith JL, D'Agostino RB, Ruthazer R, Atkins JM, Sayah AJ, Levy MK, Richards ME, Aufderhelde TP, Braude DA, Pirrallo RG, Doyle DD, Frascone RJ, Kosiak DJ, Learning JM, Van Gelder CM, Walter GP, Wayne MA, Woolard RH, Opie LH, Rackley CE, Apstein CS, Udelson JE: Out-of-hospital administration of intravenous glucose-insulin-potassium in patients with suspected acute coronary syndromes. The IMMEDIATE randomized controlled trial. JAMA 2012, 307:1925-1933.

9. Nurmi J, Lindsberg PJ, Häppölä O, Klementti E, Westerbacka J, Castrén M: Strict glucose control after acute stroke can be provided in the prehospital setting. Acad Emerg Med 2011, 8:436-439.

10. Nurmi J, Boyd J, Anttalainen N, Westerbacka J, Kuisma M: Early increase in blood glucose in patients resuscitated from out-of hospital ventricular fibrillation predicts poor outcome. Diabetes Care 2012, 35:510-520.
11. Ishihara M, Kagawa E, Inoue I, Kawagoe T, Shimatani Y, Kurisu S, Nakama Y, Maruhashi T, Ookawa K, Dai K, Aokage Y: Impact of admission hyperglycemia and diabetes mellitus on short- and long-term mortality after acute myocardial infarction in the coronary intervention era. Am J Cardiol 2007, 999:1674-1679.

12. Dungan KM, Braithwaite SS, Preiser JC: Stress hyperglycemia. Lancet 2009, 373:1798-1807.

13. Sarazawa K, Nakano A, Uzui H, Mitsuke Y, Geshi T, Okazawa H, Ueda T, Lee JD: Acute hyperglycemia causes microvascular damage, leading to poor functional recovery and remodeling in patients with reperfused ST-segment elevation myocardial infarction. J Nucl Cardiol 2012, 19:507-514.

14. Ishihara M: Acute hyperglycemia in patients with acute myocardial infarction. Circ J 2012, 76:563-571.

15. Iwakura K, Ito H, Ikushima M, Kawano S, Okamura A, Asano K, Kuroda T, Tanaka K, Masuyama T, Hori M, Fujii K: Association between hyperglycemia and the no-reflow phenomenon in patients with acute myocardial infarction. J Am Coll Cardiol 2003, 41:1-7.

16. Mehta SR, Yusuf S, Díaz R, Zhu J, Pais P, Xavier D, Paolasso E, Ahmed R, Xie C, Kazmi K, Tai J, Orlandi A, Pougue J, Liu L, CREATE.ECLA Trial Group Investigators: Effect of glucose-insulin-potassium infusion on mortality in patients with acute ST-segment Elevation Myocardial Infarction: The CREATE-ECLA randomized controlled trial. JAMA 2005, 293:437-446.

17. Chaudhuri A, Janicke D, Wilson MF: Anti-inflammatory and profibrinolytic effect of insulin in acute ST-segment-elevation myocardial infarction. Circulation 2004, 109:849-854.

doi:10.1186/1757-7241-22-30

Cite this article as: Vihonen et al:: Ultra-acute increase in blood glucose during prehospital phase is associated with worse short-term and long-term survival in ST-elevation myocardial infarction. Scandinavian Journal of Trauma, Resuscitation and Emergency Medicine 2014 22:30.

\section{Submit your next manuscript to BioMed Central and take full advantage of:}

- Convenient online submission

- Thorough peer review

- No space constraints or color figure charges

- Immediate publication on acceptance

- Inclusion in PubMed, CAS, Scopus and Google Scholar

- Research which is freely available for redistribution 